\title{
Enhanced antitumor activity of surface-modified iron oxide nanoparticles and an $\alpha$-tocopherol derivative in a rat model of mammary gland
} carcinosarcoma

\author{
This article was published in the following Dove Press journal: \\ International Journal of Nanomedicine \\ 6 June 2017 \\ Number of times this article has been viewed
}

\section{Daniel Horák' \\ Vitaliy Igorovych Pustovyy ${ }^{2}$ \\ Andrii Valeriyovich \\ Babinskyi² \\ Olga Mikhailovna Palyvoda ${ }^{2}$ \\ Vasyl Fedorovich Chekhun ${ }^{3}$ \\ Igor Nikolaevich Todor ${ }^{3}$ \\ Oleksandr Ivanovich \\ Kuzmenko ${ }^{2}$ \\ 'Department of Polymer Particles, Institute of Macromolecular \\ Chemistry AS CR, Prague, Czech Republic; ${ }^{2}$ Department of Vitamins and Coenzyme Biochemistry, Palladin Institute of Biochemistry, NASU, \\ Ukraine; ${ }^{3}$ Department of Mechanisms of Antitumor Therapy, R. E. Kavetsky Institute of Experimental Pathology, Oncology and Radiobiology, NASU, Ukraine}

Correspondence: Daniel Horák Department of Polymer Particles, Institute of Macromolecular Chemistry AS CR, Heyrovsky Sq 2, 16206 Prague 6, Czech Republic

Tel +420296809260

Fax +420296809410

Email horak@imc.cas.cz
Abstract: Maghemite $\left(\gamma-\mathrm{Fe}_{2} \mathrm{O}_{3}\right)$ nanoparticles were obtained by coprecipitation of ferrous and ferric salts in an alkaline medium followed by oxidation; the nanoparticles were coated with poly $(N, N$-dimethylacrylamide) (PDMA) and characterized by transmission electron microscopy, attenuated total reflection (ATR) Fourier transform infrared (FTIR) spectroscopy, dynamic light scattering, thermogravimetric and elemental analyses, and magnetic measurements in terms of particle morphology, size, polydispersity, amount of coating, and magnetization, respectively. The effects of $\alpha$-tocopherol (Toc) and its phenolic (Toc-6-OH) and acetate (Toc6-Ac) derivatives on $\mathrm{Fe}^{2+}$ release from $\gamma-\mathrm{Fe}_{2} \mathrm{O}_{3} @$ PDMA, as well as from $\gamma-\mathrm{Fe}_{2} \mathrm{O}_{3}$ and $\mathrm{CuFe}_{2} \mathrm{O}_{4}$ nanoparticles (controls), were examined in vitro using 1,10-phenanthroline. The presence of tocopherols enhanced spontaneous $\mathrm{Fe}^{2+}$ release from nanoparticles, with Toc-6-OH exhibiting more activity than neat Toc. All of the nanoparticles tested were found to initiate blood lipid oxidation in a concentration-dependent manner, as determined by analysis of 2-thiobarbituric acid reactive species. Wistar rats with Walker-256 carcinosarcoma (a model of mammary gland carcinosarcoma) received Toc-6-Ac, magnetic nanoparticles, or their combination per os, and the antitumor activity of each treatment was determined in vivo. $\gamma-\mathrm{Fe}_{2} \mathrm{O}_{3} @$ PDMA nanoparticles exhibited increased antitumor activity compared to both commercial $\mathrm{CuFe}_{2} \mathrm{O}_{4}$ particles and the antitumor drug doxorubicin. Moreover, increased antitumor activity was observed after combined administration of $\gamma-\mathrm{Fe}_{2} \mathrm{O}_{3}$ @PDMA nanoparticles and Toc-6-Ac; however, levels of bilirubin, aspartate aminotransferase, and white bloods normalized and did not differ from those of the intact controls. The antitumor activity of the $\gamma-\mathrm{Fe}_{2} \mathrm{O}_{3}$ nanoparticles strongly correlated with $\mathrm{Fe}^{2+}$ release from the nanoparticles but not with nanoparticle-initiated lipid peroxidation in vitro.

Keywords: iron oxide nanoparticles, poly ( $N, N$-dimethylacrylamide), lipid oxidation, oxidative stress, antitumor activity, $\alpha$-tocopherol

\section{Introduction}

Colloidal nanoparticles (eg, $\mathrm{Au}$ and $\mathrm{Ag}$ ) are widely used for cancer treatment in experimental oncology. ${ }^{1}$ Moreover, iron oxide nanoparticles, measuring 5-20 nm, have become extremely popular in various industrial, laboratory, and biomedical applications, including diagnostics and treatment. ${ }^{2}$ In particular, magnetic targeting is a very attractive strategy that is used to deliver particles and fix them to the desired target area using a magnetic field. Magnetic nanoparticles, thus, serve in drug delivery systems, cell labeling, and as contrast agents in MRI. Various beneficial effects of certain nanoparticles on cancer treatment have also been described. ${ }^{3,4}$ Iron oxide 
nanoparticles - namely, maghemite $\left(\gamma-\mathrm{Fe}_{2} \mathrm{O}_{3}\right)$ or magnetite $\left(\mathrm{Fe}_{3} \mathrm{O}_{4}\right)$ - are advantageous because their biocompatibility has already been demonstrated..$^{5}$ Another benefit of iron oxide nanoparticles is their superparamagnetic behavior, as they do not retain any magnetism after removal from the magnetic field, but they are attracted to a magnet. Superparamagnetic particles have dimensions smaller than a particular magnetic domain. ${ }^{6}$ Their main advantages are manipulability, targetability by a magnet, easy magnetic separation, and monitoring by MRI.

Many chemical approaches, such as coprecipitation, solgel, microemulsion, sonochemical, hydrothermal, and solvothermal methods, as well as electrochemical deposition under oxidized conditions, thermal decomposition, and biomimetic synthesis have been used to prepare superparamagnetic iron oxide nanoparticles. ${ }^{7}$ Other reports have described surface reactions on magnetic nanoparticles that can be performed either during synthesis or by a post-synthesis modification. Among coating methods, atom-transfer radical polymerization has a special role. ${ }^{8}$ Coating should ensure colloidal stability of the particles in aqueous media, inhibit undesirable protein adsorption, and allow binding to drugs or other target biomolecules. Coatings of silica, ${ }^{9}$ poly(ethylene glycol), ${ }^{10}$ poly(vinyl alcohol), ${ }^{11}$ polyvinylpyrrolidone, ${ }^{12}$ poly(acrylic acid), ${ }^{13}$ poly(methyl methacrylate), ${ }^{14}$ chitosan, ${ }^{15}$ dextran, ${ }^{16}$ starch, ${ }^{17}$ ethyl cellulose, ${ }^{18}$ albumin, ${ }^{19}$ and gelatin ${ }^{20}$ have been described.

Vitamin E ( $\alpha$-tocopherol) is well-known for its strong affinity to biomembranes due to its interactions with phospholipids; however, it lacks antitumor, as well as antimetastatic, activity. By contrast, synthesized short-chain vitamin $\mathrm{E}$ analogs exhibit excellent anticancer activity ${ }^{21}$ and are, therefore, recommended for prophylaxis and cancer treatment. One disadvantage of $\alpha$-tocopherol (Toc) is its lipophilicity, which is associated with difficulties in preparing environment-friendly aqueous dispersions..$^{22,23}$ This lipophilicity can be overcome by encapsulating Toc into suitable polymers ${ }^{24}$ or using biocompatible surfactants ${ }^{25}$ or water-soluble vitamin E derivatives. ${ }^{26} D$ - $\alpha$-tocopheryl poly(ethylene glycol) succinate (vitamin E TPGS NF) is commercially available from Eastman ${ }^{27}$ and is used as an emulsifier, surfactant, drug solubilizer, absorption enhancer, and vehicle for lipid-based drug delivery formulations. For example, vitamin E TPGS NF-coated magnetic polylactide and polyglycolide nanoparticles are suitable for multimodal MRI and fluorescence imaging. ${ }^{28}$ An aqueous dispersion of magnetic particles coated with another water-soluble lowmolecular-weight derivative of vitamin E called Trolox (6-hydroxy-2,5,7,8-tetramethyl-chroman-2-carboxylic acid) was tested as a radical scavenger. ${ }^{29}$

Despite extensive investigations on magnetic nanoparticles, their redox capacity and anticancer activity are still not fully understood. Here, we describe the preparation of novel surface-modified iron oxide nanoparticles and demonstrate their in vitro $\mathrm{Fe}^{2+}$ release and antitumor activity, which are synergistically increased by the addition of the phenolic derivative of Toc (Toc-6-OH). The biological activity of these nanoparticles is compared with that of commercially available magnetic nanoparticles exemplified by $\mathrm{CuFe}_{2} \mathrm{O}_{4}$. This work is a continuation of our previous reports on the use of poly( $N, N$-dimethylacrylamide) (PDMA)-coated maghemite nanoparticles for stem cell and macrophage labeling. ${ }^{30,31}$

\section{Methods \\ Materials}

$\mathrm{FeCl}_{2} \cdot 4 \mathrm{H}_{2} \mathrm{O}, \mathrm{FeCl}_{3} \cdot 6 \mathrm{H}_{2} \mathrm{O}, N, N$-dimethylacrylamide (DMA), 4,4'-azobis(4-cyanovaleric acid) (ACVA), $\mathrm{NaCl}$, Tris, thiobarbituric acid (TBA), trichloroacetic acid, copper iron oxide $\left(\mathrm{CuFe}_{2} \mathrm{O}_{4}\right), 1,10$-phenanthroline, Toc, and cell culture medium 199 were obtained from Sigma-Aldrich (St Louis, MO, USA). The Toc derivative with an isoprenoid side chain shortened to 6 carbon atoms (Figure 1) was synthesized both in its phenolic (Toc-6-OH) and acetate forms (Toc-6-Ac) according to a method described previously. ${ }^{21}$ Doxorubicin was obtained from Arterium (Kiev, Ukraine), and a sodium hypochlorite solution was obtained from Bochemie (Bohumín, Czech Republic). Other reagents and solvents were purchased from LachNer (Neratovice, Czech Republic).

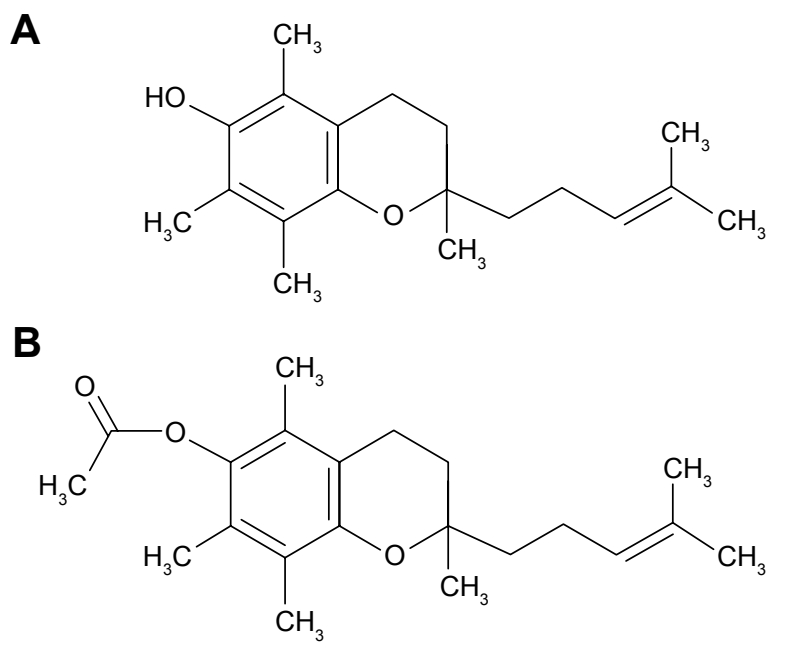

Figure I $\alpha$-Tocopherol derivative with an isoprenoid side chain shortened to 6 carbon atoms in $(\mathbf{A})$ phenolic and $(\mathbf{B})$ acetate forms. 
Ultrapure Q water, ultrafiltered in a Milli-Q Gradient A10 system (Millipore; Molsheim, France), was used to prepare solutions.

\section{Preparation of poly $(\mathrm{N}, \mathrm{N}-$ dimethylacrylamide)-modified $\gamma$ - $\mathrm{Fe}_{2} \mathrm{O}_{3}$ nanoparticles}

$\gamma$ - $\mathrm{Fe}_{2} \mathrm{O}_{3}$ was prepared from $\mathrm{FeCl}_{3}, \mathrm{FeCl}_{2}(2: 1, \mathrm{~mol} / \mathrm{mol})$, and $\mathrm{NH}_{4} \mathrm{OH}$, followed by oxidation with sodium hypochlorite. ${ }^{32}$ Uncoated $\gamma-\mathrm{Fe}_{2} \mathrm{O}_{3}$ served both as a control in animal experiments and as a starting material for the preparation of polymer-modified particles. To prepare $\operatorname{poly}(\mathrm{N}, \mathrm{N}$ dimethylacrylamide), both DMA (3 g) and ACVA (10 mg) were dissolved in a toluene/tetrahydrofuran (THF) mixture (3.5:3.4 mL/mL) and polymerization was initiated by heating at $70^{\circ} \mathrm{C}$ for $8 \mathrm{~h}$ with magnetic stirring. The resulting PDMA was precipitated into diethyl ether and vacuum-dried at room temperature (RT). An aqueous PDMA $(8.8 \mathrm{mg} / \mathrm{mL})$ solution $(5 \mathrm{~mL})$ was then added to the $\gamma-\mathrm{Fe}_{2} \mathrm{O}_{3}$ ferrofluid $(5 \mathrm{~mL} ; 8.8 \mathrm{mg}$ $\gamma$ - $\mathrm{Fe}_{2} \mathrm{O}_{3} / \mathrm{mL}$ ), yielding $\gamma$ - $\mathrm{Fe}_{2} \mathrm{O}_{3} @$ PDMA nanoparticles.

\section{Physicochemical characterization}

Both particle size and particle size distribution were determined from transmission electron micrographs (TEM) using an FEI Tecnai Spirit $\mathrm{G}^{2}$ microscope (Brno, Czech Republic). The number-average diameters $\left(D_{\mathrm{n}}=\sum D_{\mathrm{i}} / \mathrm{N}\right)$, weight-average diameters $\left(D_{\mathrm{w}}=\sum D_{\mathrm{i}}^{4} / \sum D_{\mathrm{i}}^{3}\right)$, and polydispersity indexes (PDI $\left.=D_{\mathrm{w}} / D_{\mathrm{n}}\right)$ were calculated from $\sim 500$ particles using Atlas software (Tescan Digital Microscopy Imaging; Brno, Czech Republic), where $\mathrm{N}$ is the number of particles. The effect of $0.1 \mathrm{M} \mathrm{HCl}(1 \mathrm{~mL}, \mathrm{pH} 3)$ on the degradation of $\gamma-\mathrm{Fe}_{2} \mathrm{O}_{3} @$ PDMA nanoparticles $(13.2 \mu \mathrm{g})$ was determined in $1.5-\mathrm{mL}$ Eppendorf tubes after $1-\mathrm{h}$ treatment at $37^{\circ} \mathrm{C}$ with shaking (200 rpm). The hydrodynamic diameter $D_{\mathrm{h}}$, polydispersity PI, and $\zeta$-potential were measured by dynamic light scattering (DLS) with a Malvern Instruments Autosizer Lo-C (Malvern, UK). Elemental analysis was performed on a PerkinElmer 2400 CHN apparatus (Norwalk, CT, USA). The molecular weight of PDMA was determined by sizeexclusion chromatography (SEC) on a gradient Knauer system (Berlin, Germany) with detection using diode array and Alltech 3300 evaporative light scattering. A Phenomenex PolySept-GFC-P linear column (Torrance, CA, USA) was used in isocratic $0.03 \mathrm{M}$ ammonium acetate buffer in $\mathrm{CH}_{3} \mathrm{CN} /$ water $(20: 80, \mathrm{v} / \mathrm{v})$. Infrared spectra were measured on a Perkin Elmer PARAGON 1000 PC Fourier transform infrared (FTIR) spectrometer equipped with a Specac MKII Golden Gate Single Reflection ATR System with diamond crystals. Magnetic properties were measured on a SQUID MPMS5 magnetometer (Quantum Design; San Diego, USA) at $300 \mathrm{~K}$. The relative content of polymer and $\gamma-\mathrm{Fe}_{2} \mathrm{O}_{3}$ was determined using a Perkin Elmer TGA 7 thermogravimetric analyzer (Norwalk, CT, USA). Particles were heated from RT to $800^{\circ} \mathrm{C}$ at a heating rate of $10^{\circ} \mathrm{C} / \mathrm{min}$.

\section{Determination of $\mathrm{Fe}^{2+}$ release from the nanoparticles}

The concentration of $\mathrm{Fe}^{2+}$ released from iron oxide nanoparticles was determined using a colorimetric method with a $\mathrm{Fe}^{2+}-1,10$-phenanthroline complex by measuring absorbance at $510 \mathrm{~nm}$ on an MQX 200 BioTek UV spectrophotometer (Winooski, VT, USA). ${ }^{32}$ The reaction mixture contained a 0.25 -mg nanoparticles/mL, 0.005 wt. $\%$ of 1,10 -phenanthroline solution in ethanol (added before incubation to bind the released $\mathrm{Fe}^{2+}$ and to prevent its oxidation to $\mathrm{Fe}^{3+}$ ) and Toc or Toc-6-OH at concentrations ranging from 100 to $1,000 \mu \mathrm{M}$. The reactions were run in $0.9 \% \mathrm{NaCl}$ solution and $10 \mathrm{mM}$ Tris (pH 7.4) at $37^{\circ} \mathrm{C}$ for $24 \mathrm{~h}$ with shaking (200 rpm). The nanoparticles were then separated by centrifugation at $1,500 \mathrm{~g}$ for $15 \mathrm{~min}$, and the absorbance of the colored complex, which is directly proportional to the $\mathrm{Fe}^{2+}$ concentration, was analyzed in the supernatant. $\mathrm{Fe}^{2+}$ release from the nanoparticles in the absence of Tocs served as a control.

\section{Preparation of blood serum}

Blood serum was obtained from Wistar rats weighing 250-300 g. Immediately after euthanasia, blood $(\sim 5 \mathrm{~mL})$ was taken by heart puncture with a syringe and transferred into a centrifuge tube that was left to stand at RT for $30 \mathrm{~min}$. Blood was then separated by centrifugation at $1,500 \mathrm{~g}$ for $15 \mathrm{~min}$, and serum was stored in polystyrene tubes at $-80^{\circ} \mathrm{C}$ before blood lipid oxidation tests.

\section{Preparation of whole blood and blood plasma and determination of liver enzymatic activities}

Blood ( $\sim 5 \mathrm{~mL})$ taken by the above procedure was transferred into a Li-heparin blood collection tube (Vacutest Kima; Arzergande, Italy). The tube was inverted twice and blood cells were counted in a PCE210 hematology particle counter (Erma; Tokyo, Japan). The remainder of the blood was centrifuged at 1,500 $\mathrm{g}$ for $15 \mathrm{~min}$ to separate cells from the plasma. Bilirubin $^{33}$ and activities of alanine aminotransferase (ALT) ${ }^{34}$ and aspartate aminotransferase (AST) ${ }^{35}$ were determined using a biochemistry and immunochemistry analyzer 2990 (Global Biomarketing Group; Palo Alto, CA, USA). 


\section{Blood lipid oxidation}

Lipid oxidation was determined by measuring 2-thiobarbituric acid reactive species (TBARS). ${ }^{36}$ Nanoparticles were incubated with blood serum $(25 \mu \mathrm{L})$ in $0.9 \% \mathrm{NaCl}$ and $10 \mathrm{mM}$ Tris ( $\mathrm{pH} 7.4$ ) at $37^{\circ} \mathrm{C}$ for $24 \mathrm{~h}$ with shaking (200 rpm). After incubation, $0.375 \%$ TBA, $15 \%$ trichloroacetic acid, and $0.25 \mathrm{M} \mathrm{HCl}$ were added, and the mixture was heated at $95^{\circ} \mathrm{C}$ for $30 \mathrm{~min}$. Protein pellets were separated from the supernatant by centrifugation at 3,000 $\mathrm{g}$ for $15 \mathrm{~min}$. Aliquots of the supernatant $(200 \mu \mathrm{L})$ were analyzed on an MQX 200 BioTek spectrophotometer (Winooski, VT, USA) at $540 \mathrm{~nm}$. Malondialdehyde standards were used for TBARS calibration, and neat serum served as a control.

\section{Antitumor activity}

Walker-256 carcinosarcoma (W-256) female Wistar rats weighing $150 \mathrm{~g}$ served as an in vivo mammary gland tumor model. For tumor inoculation, a suspension of $23 \% \mathrm{~W}-256$ tumor tissue in cell culture medium $199(0.4 \mathrm{~mL})$ was subcutaneously injected into the back of each animal. Animals were divided into the following groups: 1) without any treatment (except saline), which served as a control; or treated with 2) doxorubicin $(1.5 \mathrm{mg} / \mathrm{kg})$, typically on day 3 after W-256 transplantation when tumor size reached 7-10 mm and 3) Toc-6-Ac, 4) $\left.\left.\mathrm{CuFe}_{2} \mathrm{O}_{4}, 5\right) \gamma-\mathrm{Fe}_{2} \mathrm{O}_{3}, 6\right) \gamma-\mathrm{Fe}_{2} \mathrm{O}_{3}$ @ PDMA, 7) $\mathrm{CuFe}_{2} \mathrm{O}_{4}$ and Toc-6-Ac, 8) $\gamma-\mathrm{Fe}_{2} \mathrm{O}_{3}$ and Toc-6-Ac, or 9) $\gamma-\mathrm{Fe}_{2} \mathrm{O}_{3} @$ PDMA and Toc-6-Ac. With the exception of 2 ), where doxorubicin was administered intraperitoneally due to its poor bioavailability after the oral administration, ${ }^{37}$ the other agents ( $25 \mathrm{mg}$ of Toc- 6 -Ac and $10 \mathrm{mg}$ of the nanoparticles per $\mathrm{kg}$ ) were administered per os into the stomach in all of the other experiments. Each group consisted of five to seven animals. Animals received five injections of doxorubicin, $\mathrm{CuFe}_{2} \mathrm{O}_{4}, \gamma-\mathrm{Fe}_{2} \mathrm{O}_{3}$, or $\gamma-\mathrm{Fe}_{2} \mathrm{O}_{3} @$ PDMA nanoparticles; or 10 injections of Toc-6-Ac for 10 days. At the end of the experiment, the tumor size was measured with a caliper, and tumor volume (V) was calculated using the following formula: ${ }^{38}$

$$
V=(4 / 3) \times \pi \times(L / 2) \times(W / 2) \times(D / 2) / 1000
$$

where $L, W$, and $D$ represent the tumor length, width, and depth $(\mathrm{mm})$, respectively. The mean tumor volume was calculated in $\mathrm{cm}^{3}$, and the SE for each group was determined.

\section{Ethical issues of animal use}

Experiments conducted on non-transgenic Wistar female rats were performed according to European Commission regulations and were approved by the ethical committees of the Palladin Institute of Biochemistry and the R.E. Kavetsky Institute of Experimental Pathology, Oncology and Radiobiology. Rats were kept in a special facility and euthanized through carbon dioxide asphyxiation before necropsy. ${ }^{39,40}$

\section{Statistical analysis}

Two-tailed Student's $t$-test was used for comparisons between experimental groups. The level of significance was set at $P<0.05$. All data are presented as the mean \pm SE.

\section{Results and discussion}

\section{Superparamagnetic $\gamma$ - $\mathrm{Fe}_{2} \mathrm{O}_{3}$ nanoparticles} In the present work, superparamagnetic iron oxide nanoparticles were synthesized by coprecipitation using ammonium hydroxide as the precipitation agent. ${ }^{41}$ The resulting $\mathrm{Fe}_{3} \mathrm{O}_{4}$ nanoparticles were oxidized to $\gamma-\mathrm{Fe}_{2} \mathrm{O}_{3}$, which is preferred to $\mathrm{Fe}_{3} \mathrm{O}_{4}$ due to its resistance to uncontrolled oxidation that often results in non-magnetic products. Superparamagnetic iron oxides can be magnetized in an external magnetic field. However, in its absence, magnetization disappears and the particles become dispersible in water. The surface of the $\gamma-\mathrm{Fe}_{2} \mathrm{O}_{3}$ nanoparticles must be modified to make them both colloidally stable in aqueous media and to enable penetration of the nanoparticles into cells. PDMA was selected as the nanoparticle coating due to its hydrophilicity, excellent biocompatibility, and minimal non-specific protein adsorption. ${ }^{42}$ PDMA was obtained by ACVA-initiated polymerization of DMA in a toluene/THF solution. One advantage of ACVA is the presence of carboxyl groups, which form complexes with Fe ions, thus facilitating attachment of the polymerization initiator to the surface of iron oxide..$^{43}$ The carboxyl groups of ACVA also offer the possibility of the attachment of anticancer drugs containing $\mathrm{OH}$ and/or $\mathrm{NH}_{2}$ groups, such as etoposide, doxorubicin, genistein, and topotecan, for targeted drug delivery. ${ }^{44}$ According to the elemental analysis, PDMA contained 59.5, 13.6, and $10.1 \mathrm{wt} . \%$ of $\mathrm{C}, \mathrm{N}$, and $\mathrm{H}$, respectively. The rather small discrepancy in the calculated values (C 60.6, N 14.1, and H 9.2 wt.\%) may be caused by the presence of residual water in the polymer. According to SEC, the molecular weight of PDMA was $\sim 50,000 \mathrm{Da}$, with a relatively broad distribution caused by chain-transfer reactions with the solvent (THF). It should be noted that such a molecular weight does not exceed the renal threshold. ${ }^{45}$ According to TEM (Figure 2A and B), the size of uncoated and coated nanoparticles was similar $(12 \mathrm{~nm})$. In addition, the PDI (1.12) remained unchanged and rather low, indicating the absence of undesirable aggregation. For comparison purposes, the size of commercial $\mathrm{CuFe}_{2} \mathrm{O}_{4}$ nanoparticles 

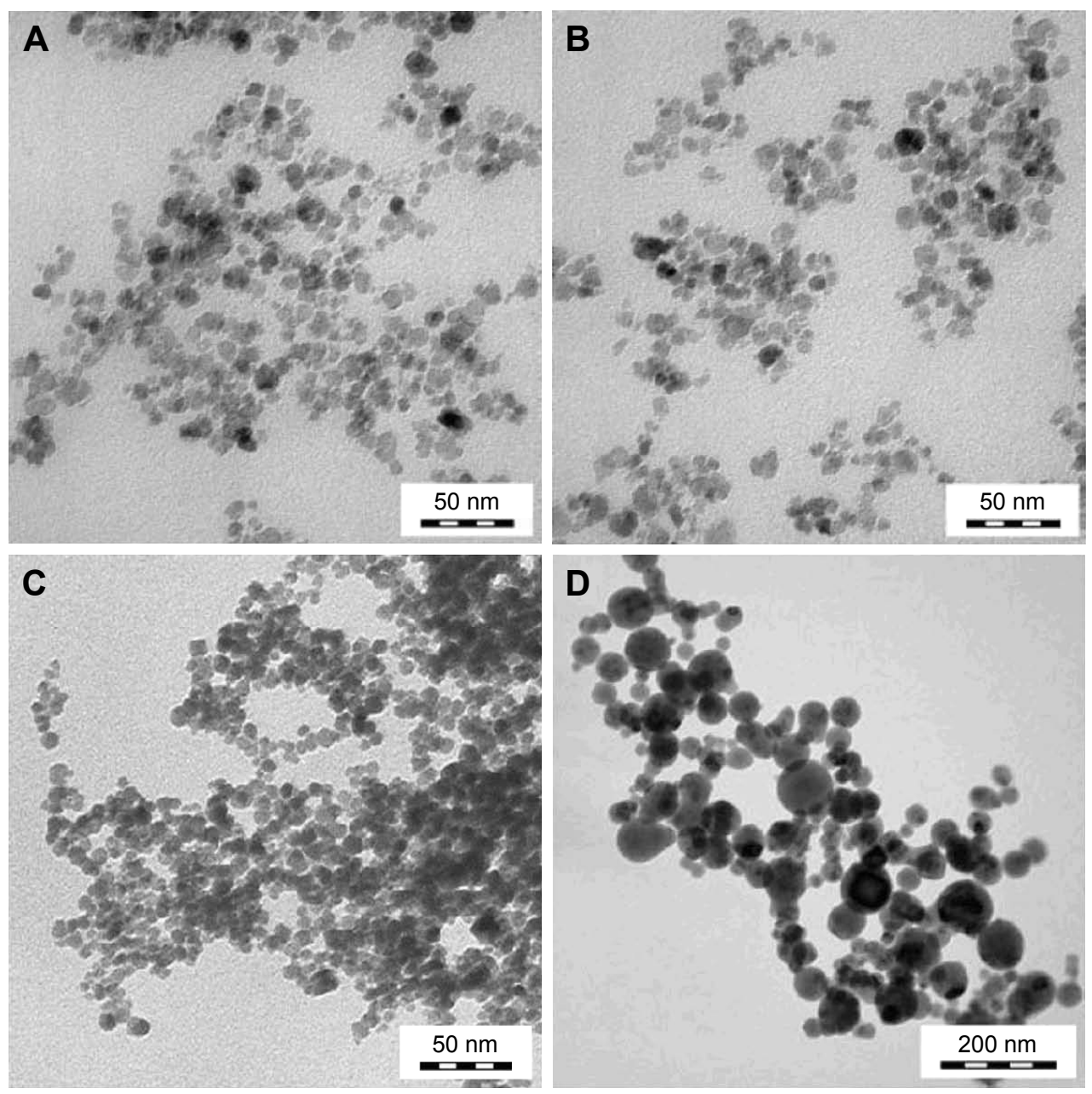

Figure 2 Transmission electron micrographs of $(\mathbf{A}) \gamma-\mathrm{Fe}_{2} \mathrm{O}_{3}$ and $(\mathbf{B}) \gamma-\mathrm{Fe}_{2} \mathrm{O}_{3} @ P D M A$ nanoparticles before and $(\mathbf{C})$ after incubation in $0 . \mathrm{I} \mathrm{M} \mathrm{HCl}(\mathrm{pH} 3)$ at $37^{\circ} \mathrm{C}$ for I h, and (D) $\mathrm{CuFe}_{2} \mathrm{O}_{4}$ nanoparticles.

was relatively large $(40 \mathrm{~nm})$ with a very broad particle size distribution (PDI $=1.42$; Figure 2D). As the $\mathrm{pH}$ in the gastrointestinal tract of mammals is an important factor affecting the stability and solubility of drugs, food, and its supplements, the effect of $0.1 \mathrm{M} \mathrm{HCl}$, which mimics the stomach environment ( $\mathrm{pH} \mathrm{3)},{ }^{46}$ on the dissolution of nanoparticles was investigated. It was determined that $0.1 \mathrm{M} \mathrm{HCl}$ did not degrade $\gamma-\mathrm{Fe}_{2} \mathrm{O}_{3} @$ PDMA particles (Figure 2C).

DLS measurements revealed that the hydrodynamic diameter of starting $\gamma-\mathrm{Fe}_{2} \mathrm{O}_{3}$ was larger $\left(D_{\mathrm{h}}=54 \mathrm{~nm}\right)$ than the number-average diameter $\left(D_{\mathrm{n}}\right)$ from TEM, and the polydispersity PI of 0.14 roughly corresponded with PDI (according to TEM). Compared to neat $\gamma-\mathrm{Fe}_{2} \mathrm{O}_{3}$, both the hydrodynamic diameter $\left(D_{\mathrm{h}}=72 \mathrm{~nm}\right)$ and polydispersity $(\mathrm{PI}=0.19)$ of the $\gamma-\mathrm{Fe}_{2} \mathrm{O}_{3} @ \mathrm{PDMA}$ nanoparticles were slightly larger due to the polymer coating. It should be noted that the polydispersity PI, according to DLS, differed substantially from the polydispersity index PDI according to TEM, where a PDI of 1 represents monodispersed particles, whereas polydispersed particles typically exhibit PDIs $>1.05$. DLS always yields a larger particle size compared to TEM due to principal differences in both measurements and the statistical treatment. It should also be noted that, whereas the former method measures particles in water, the latter measures particles in the dry state. High absolute values of the $\zeta$-potential of both coated $(-35.8 \mathrm{mV})$ and uncoated $(-44 \mathrm{mV}) \gamma-\mathrm{Fe}_{2} \mathrm{O}_{3}$ particles indicated good colloidal stability. As subtle change in $\mathrm{pH}$, which decreased from $10.17\left(\gamma-\mathrm{Fe}_{2} \mathrm{O}_{3}\right)$ to $9.92\left(\gamma-\mathrm{Fe}_{2} \mathrm{O}_{3} @\right.$ PDMA), was induced by the $\mathrm{COOH}$ groups in PDMA originating from ACVA initiation.

Figure 3A shows the attenuated total reflection (ATR) FTIR spectra of pure PDMA and PDMA-coated and uncoated $\gamma-\mathrm{Fe}_{2} \mathrm{O}_{3}$ nanoparticles. The spectra of pure PDMA and $\gamma-\mathrm{Fe}_{2} \mathrm{O}_{3} @$ PDMA nanoparticles were identical, which can be attributed to the high amount of polymer relative to iron oxide $(1: 1, w / w)$. Amide bands were observed at 1,614 and $1,402 \mathrm{~cm}^{-1}$. The peaks at 1,498 and $1,354 \mathrm{~cm}^{-1}$ were ascribed to the $\mathrm{CH}_{3}$ deformation vibration. 

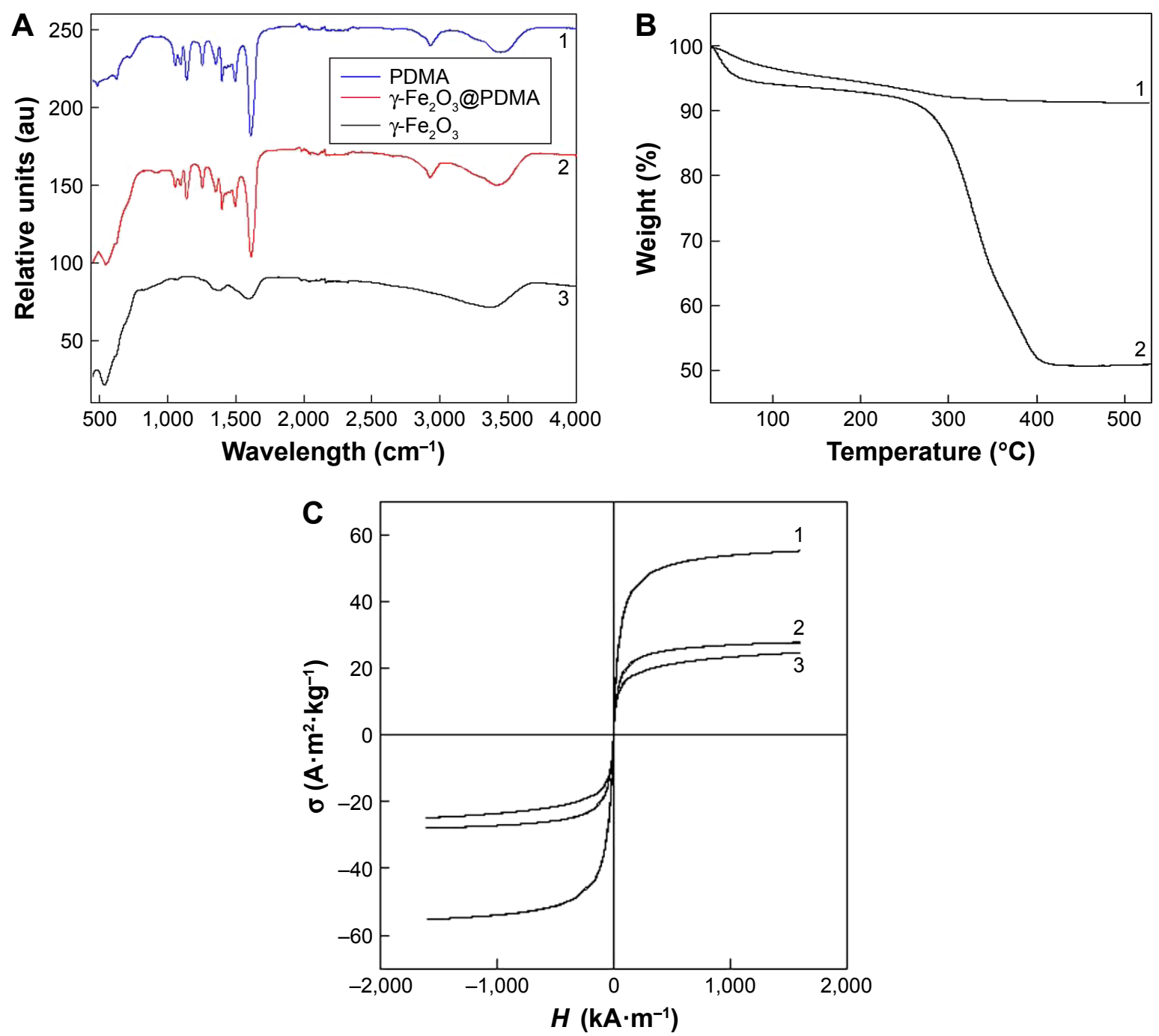

Figure 3 (A) FTIR spectra of (I) PDMA, (2) $\gamma$ - $\mathrm{Fe}_{2} \mathrm{O}_{3} @ P D M A$, and (3) $\gamma$ - $\mathrm{Fe}_{2} \mathrm{O}_{3}$ nanoparticles. (B) TGA of (I) $\gamma$ - $\mathrm{Fe}_{2} \mathrm{O}_{3}$ and (2) $\gamma$ - $\mathrm{Fe}_{2} \mathrm{O}_{3} @$ PDMA nanoparticles. (C) SQUID measurements of (I) $\gamma-\mathrm{Fe}_{2} \mathrm{O}_{3}$, (2) $\gamma$ - $-\mathrm{Fe}_{2} \mathrm{O}_{3} @ P D M A$, and (3) $\mathrm{CuFe}_{2} \mathrm{O}_{4}$ nanoparticles.

Abbreviations: TGA, thermogravimetric analysis; SQUID, superconducting quantum interference device; PDMA, poly(N,N-dimethylacrylamide); FTIR, Fourier transform infrared.

According to TGA analysis, a slight decrease in weight with heating was caused by the evaporation of water bound to $\gamma$ - $\mathrm{Fe}_{2} \mathrm{O}_{3}$ (Figure 3B). By contrast, $\gamma-\mathrm{Fe}_{2} \mathrm{O}_{3} @$ PDMA particles lost a substantial amount of weight ( $\sim 40 \mathrm{wt} . \%)$ during heating from $280^{\circ} \mathrm{C}$ to $400^{\circ} \mathrm{C}$, which roughly corresponded to the amount of polymer added in the reaction mixture during surface modification.

The superparamagnetic properties of $\gamma-\mathrm{Fe}_{2} \mathrm{O}_{3}, \gamma-\mathrm{Fe}_{2} \mathrm{O}_{3} @$ PDMA, and $\mathrm{CuFe}_{2} \mathrm{O}_{4}$ nanoparticles were confirmed on a SQUID magnetometer, as no hysteresis loops were observed (Figure 3C). The remanent magnetizations and coercivities were also low - amounting to $1.37 \mathrm{~A} \cdot \mathrm{m}^{2} \cdot \mathrm{kg}^{-1}$ and $1.69 \mathrm{kA} \cdot \mathrm{m}^{-1}$, respectively, for neat $\gamma-\mathrm{Fe}_{2} \mathrm{O}_{3}$, and $0.93 \mathrm{~A} \cdot \mathrm{m}^{2} \cdot \mathrm{kg}^{-1}$ and $1.28 \mathrm{kA} \cdot \mathrm{m}^{-1}$, respectively, for $\gamma-\mathrm{Fe}_{2} \mathrm{O}_{3} @$ PDMA particles. The saturation, remanent magnetization, and coercivity values of the $\mathrm{CuFe}_{2} \mathrm{O}_{4}$ particles were 21.16,
$0.22 \mathrm{~A} \cdot \mathrm{m}^{2} \cdot \mathrm{kg}^{-1}$, and $0.35 \mathrm{kA} \cdot \mathrm{m}^{-1}$, respectively, which were lower than those of $\gamma-\mathrm{Fe}_{2} \mathrm{O}_{3}$. A lower saturation magnetization of $\gamma-\mathrm{Fe}_{2} \mathrm{O}_{3}\left(53 \mathrm{~A} \cdot \mathrm{m}^{2} \cdot \mathrm{kg}^{-1}\right)$ relative to that of bulk $\gamma-\mathrm{Fe}_{2} \mathrm{O}_{3}$ (60-80 A $\left.\cdot \mathrm{m}^{2} \cdot \mathrm{kg}^{-1}\right)^{5}$ indicated the presence of impurities and/or water, which was confirmed by FTIR spectroscopy and TGA. The saturation magnetization of the $\gamma-\mathrm{Fe}_{2} \mathrm{O}_{3} @$ PDMA nanoparticles was $26.1 \mathrm{~A} \cdot \mathrm{m}^{2} \cdot \mathrm{kg}^{-1}$, suggesting that the composite particles contained 49 wt.\% of PDMA, roughly corresponding to the amount of polymer coating determined by TGA.

\section{$\mathrm{Fe}^{2+}$ release}

In vitro $\mathrm{Fe}^{2+}$ release from $\mathrm{CuFe}_{2} \mathrm{O}_{4}, \gamma-\mathrm{Fe}_{2} \mathrm{O}_{3}$, and $\gamma-\mathrm{Fe}_{2} \mathrm{O}_{3} @$ PDMA nanoparticles is shown in Figure 4. The presence of Toc-6-OH in the incubation medium induced a higher amount of $\mathrm{Fe}^{2+}$ released from the nanoparticles compared 

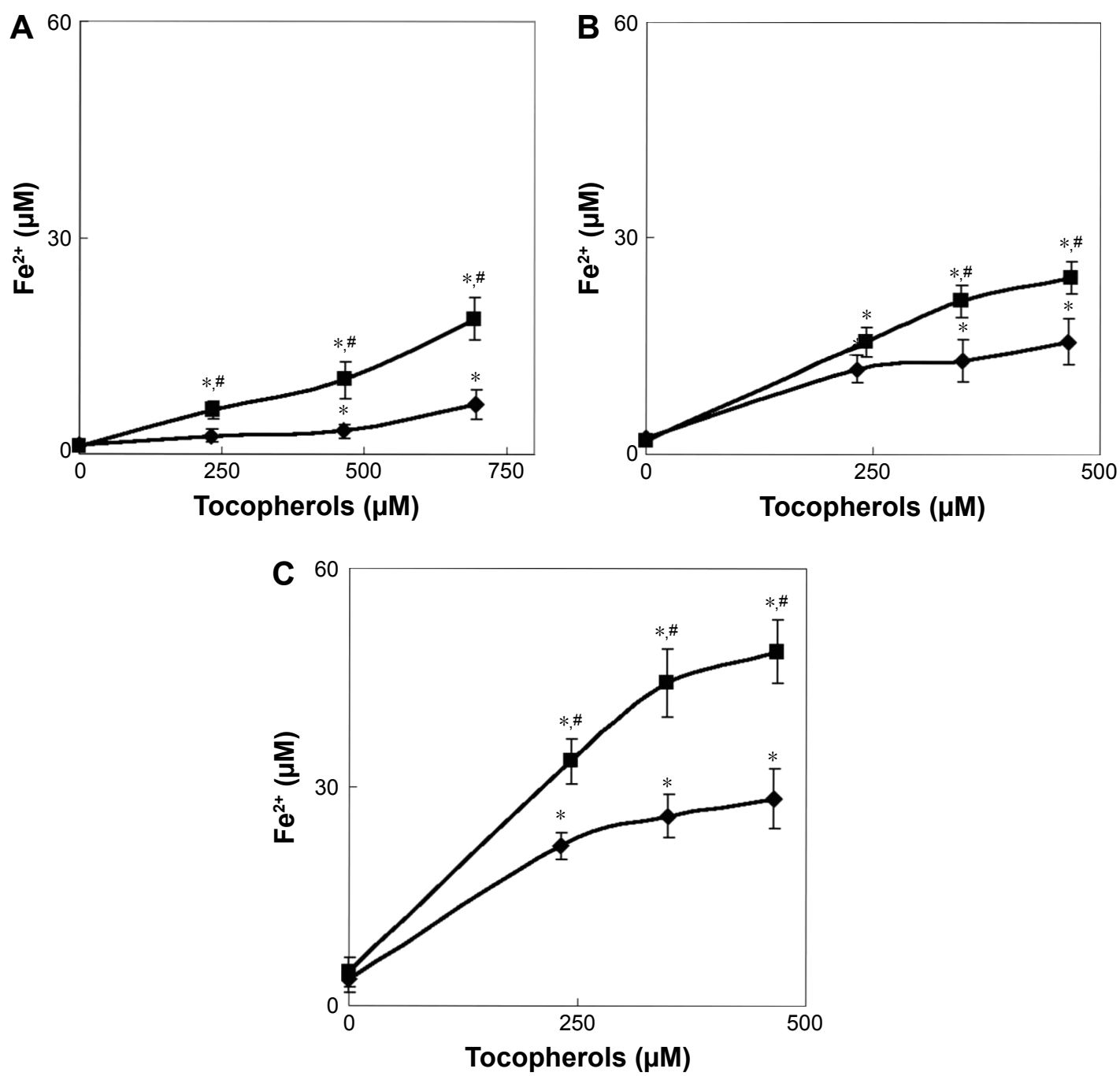

Figure $4 \mathrm{In}$ vitro $\mathrm{Fe}^{2+}$ release from $(\mathbf{A}) \mathrm{CuFe}_{2} \mathrm{O}_{4},(\mathbf{B}) \gamma-\mathrm{Fe}_{2} \mathrm{O}_{3}$, and $(\mathbf{C}) \gamma-\mathrm{Fe}_{2} \mathrm{O}_{3} @$ PDMA nanoparticles in the presence of different concentrations of $(\bullet)$ Toc and $(\mathbf{-})$ Toc-6-OH. Nanoparticles $(250 \mu \mathrm{g} / \mathrm{mL})$ were incubated in a $0.9 \% \mathrm{NaCl}$ solution and $10 \mathrm{mM}$ Tris $(\mathrm{pH} 7.4)$ at $37^{\circ} \mathrm{C}$ for $24 \mathrm{~h}$. Data are presented as the mean $\pm \mathrm{SE}(\mathrm{n}=5-8)$. *Significantly different from the absence of Toc and Toc-6-OH. "Significantly different from Toc.

to that with the same amount of Toc. The amount of $\mathrm{Fe}^{2+}$ released from $\mathrm{CuFe}_{2} \mathrm{O}_{4}$ nanoparticles (Figure 4A) was lower compared to that released from $\gamma-\mathrm{Fe}_{2} \mathrm{O}_{3}$ and $\gamma-\mathrm{Fe}_{2} \mathrm{O}_{3} @$ PDMA particles (Figure 4B and C), which is likely due to the presence of $\mathrm{Cu}^{2+}$ ions on the $\mathrm{CuFe}_{2} \mathrm{O}_{4}$ particle surface. With $\sim 470 \mu \mathrm{mol}$ of Toc-6-OH in the incubation medium, $\sim 50$ and $25 \mu \mathrm{mol}$ of $\mathrm{Fe}^{2+}$ was released from $\gamma-\mathrm{Fe}_{2} \mathrm{O}_{3} @$ PDMA and neat $\gamma-\mathrm{Fe}_{2} \mathrm{O}_{3}$ nanoparticles, respectively (Figure 4B and $\mathrm{C}$ ). It can be speculated that Toc-6-OH was more accessible to the particle surface due to its shorter side chain, compared to highly hydrophobic Toc. Therefore, penetration of Toc6-OH through the PDMA coating to the particle core was facilitated. Another possible effect influencing $\mathrm{Fe}^{2+}$ release from the particles is the higher redox activity of Toc-6-OH compared to that of Toc. The release of $\mathrm{Fe}^{2+}$ from the particles can be ascribed to a reduction of $\mathrm{Fe}^{3+}$ ions to $\mathrm{Fe}^{2+}$; this well-known reaction is used for Toc determination. ${ }^{47}$ The greater $\mathrm{Fe}^{2+}$ release from the $\gamma-\mathrm{Fe}_{2} \mathrm{O}_{3} @$ PDMA compared to that from the $\gamma-\mathrm{Fe}_{2} \mathrm{O}_{3}$ particles can be ascribed to the ability of the amide PDMA bond to form complexes with surface $\mathrm{Fe}^{3+}$ ions of maghemite, which increases its solubility product constant and induces release of $\mathrm{Fe}^{3+}$ in the solution, where $\mathrm{Fe}^{3+}$ is reduced to $\mathrm{Fe}^{2+}$.

\section{Biological experiments}

$\mathrm{As} \mathrm{Fe}^{2+}$ accelerates lipid peroxidation, ${ }^{36,48}$ the effects of $\mathrm{CuFe}_{2} \mathrm{O}_{4}, \gamma-\mathrm{Fe}_{2} \mathrm{O}_{3}$, and $\gamma-\mathrm{Fe}_{2} \mathrm{O}_{3} @$ PDMA nanoparticles on lipid oxidation in blood serum were investigated in vitro (Figure 5). Lipid peroxidation increased with increasing concentration of the particles in the blood serum; it decreased in the following order: $\mathrm{CuFe}_{2} \mathrm{O}_{4}>\gamma-\mathrm{Fe}_{2} \mathrm{O}_{3} \sim \gamma-\mathrm{Fe}_{2} \mathrm{O}_{3} @$ PDMA. Among the tested particles, the strongest effect of $\mathrm{CuFe}_{2} \mathrm{O}_{4}$ on 


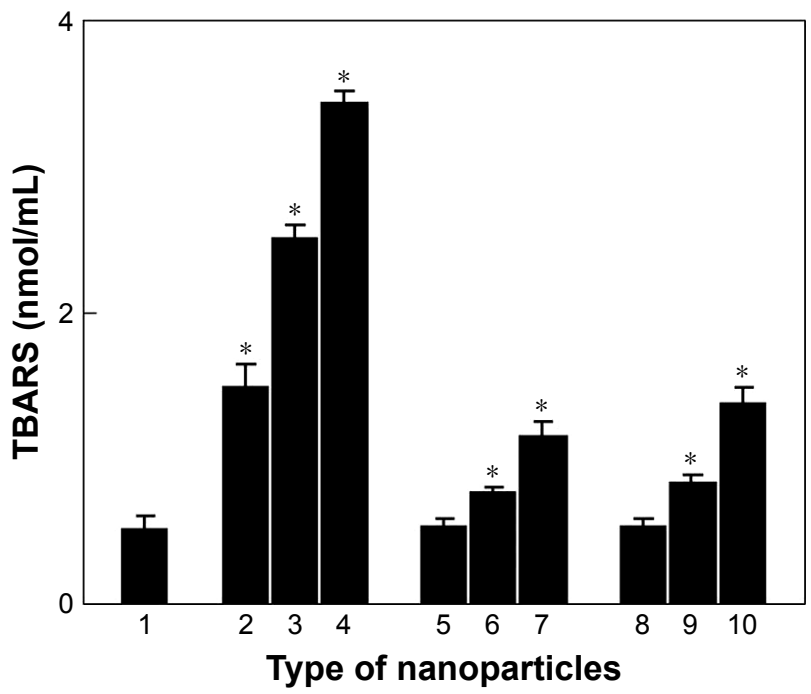

Figure 5 In vitro lipid oxidation in the blood serum in the (I) absence or (2-4) presence of $\mathrm{CuFe}_{2} \mathrm{O}_{4},(5-7) \gamma-\mathrm{Fe}_{2} \mathrm{O}_{3}$, and (8-10) $\gamma-\mathrm{Fe}_{2} \mathrm{O}_{3} @ P D M A$ nanoparticles incubated at $37^{\circ} \mathrm{C}$ for $24 \mathrm{~h} ;(2,5,8) 4.4,(3,6,9) 44$, and $(4,7,10) 444 \mu \mathrm{g}$ of particles per milliliter. Data are presented as the mean \pm SE $(n=5-8)$. *Significantly different from (I).

Abbreviations: TBARS, thiobarbituric acid reactive species; PDMA, poly(N,Ndimethylacrylamide).

lipid oxidation can be ascribed to the presence of $\mathrm{Cu}^{2+}$ ions, ${ }^{34}$ which better initiate peroxidation than $\mathrm{Fe}^{3+}$ ions. ${ }^{48}$

As the biological activity of vitamin $\mathrm{E}$ is closely related to its free hydroxyl groups, Toc-6-OH was selected for subsequent in vivo experiments. To increase the long-term storage stability of Toc, its acetate derivative (Toc-6-Ac) was used, because Toc-6-Ac is believed to behave similarly to vitamin $\mathrm{E}$ acetate, which undergoes hydrolysis in the living organism, forming the biologically active hydroxyl form of vitamin $\mathrm{E}^{49,50}$

To investigate the effect of orally administered iron oxide nanoparticles $\left(\mathrm{CuFe}_{2} \mathrm{O}_{4}, \gamma-\mathrm{Fe}_{2} \mathrm{O}_{3}, \gamma-\mathrm{Fe}_{2} \mathrm{O}_{3} @\right.$ PDMA, optionally in combination with Toc-6-Ac) on tumor growth, in vivo experiments on Wistar rats with W-256 carcinosarcoma were performed (Figure 6). The tumor volume was smaller in $\gamma-\mathrm{Fe}_{2} \mathrm{O}_{3} @$ PDMA-treated rats compared to that in animals administered $\mathrm{CuFe}_{2} \mathrm{O}_{4}$ or $\gamma-\mathrm{Fe}_{2} \mathrm{O}_{3}$ particles (Figure 7, nanoparticles no 4-6). Administration of Toc-6-Ac to tumorbearing rats decreased the tumor volume by $40 \%$ - that is, to the same extent as the clinically used anticancer drug doxorubicin. By contrast, $\gamma-\mathrm{Fe}_{2} \mathrm{O}_{3} @$ PDMA nanoparticles exhibited significantly stronger antitumor activity, decreasing the tumor volume by $60 \%$, which was consistent with previous data. ${ }^{51}$ Combined administration of nanoparticles with Toc-6-Ac decreased the tumor size to an even greater extent, and the resulting antitumor activity was significantly higher than that of doxorubicin. It can thus be hypothesized that this strong in vivo antitumor effect was induced by the nanoparticle redox activity associated with increased $\mathrm{Fe}^{2+}$
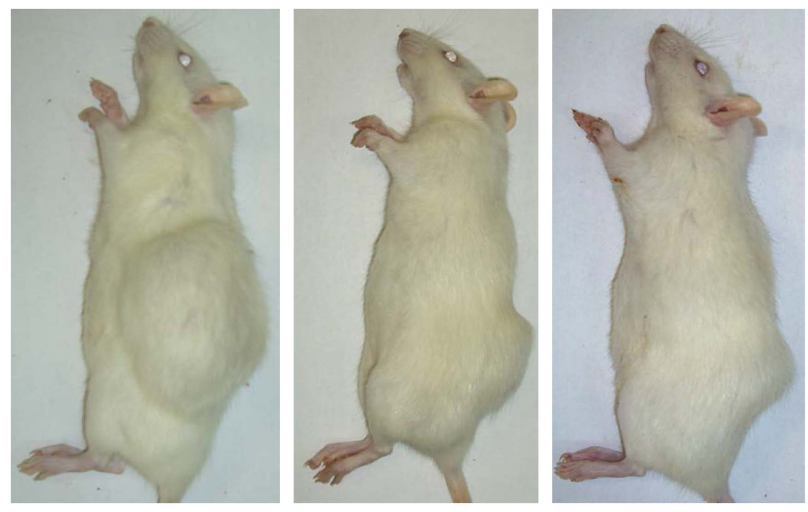

Figure 6 Antitumor effect of $\gamma$ - $\mathrm{Fe}_{2} \mathrm{O}_{3} @$ PDMA nanoparticles on Walker-256 mammary gland carcinosarcoma in Wistar rats. From left to right: untreated rat with a tumor (control), rat with a tumor treated with intraperitoneally administered doxorubicin, and rat with a tumor treated with $\gamma$ - $\mathrm{Fe}_{2} \mathrm{O}_{3} @ P D M A$ nanoparticles administered per os.

Abbreviation: PDMA, poly(N,N-dimethylacrylamide).

release from the particles in the presence of Toc-6-Ac, as previously shown in vitro (Figure 4). Iron plays an important role in tumor development ${ }^{52}$ and cancer treatment, ${ }^{53,54}$ and iron oxide nanoparticles induce dose-dependent cytotoxicity and generate oxidative stress by increasing the production of superoxide anions and nitric oxide in human umbilical endothelial cells. ${ }^{55}$ At high doses, iron oxide nanoparticles dissolve in the cytosol, and Fe ions may affect intracellular reactive oxygen species homeostasis via the Fenton reaction, ${ }^{56}$ thus generating oxidative stress to induce cell toxicity. ${ }^{57,58}$ By contrast, lipid peroxidation does not appear to play a significant role in the antitumor activity of the

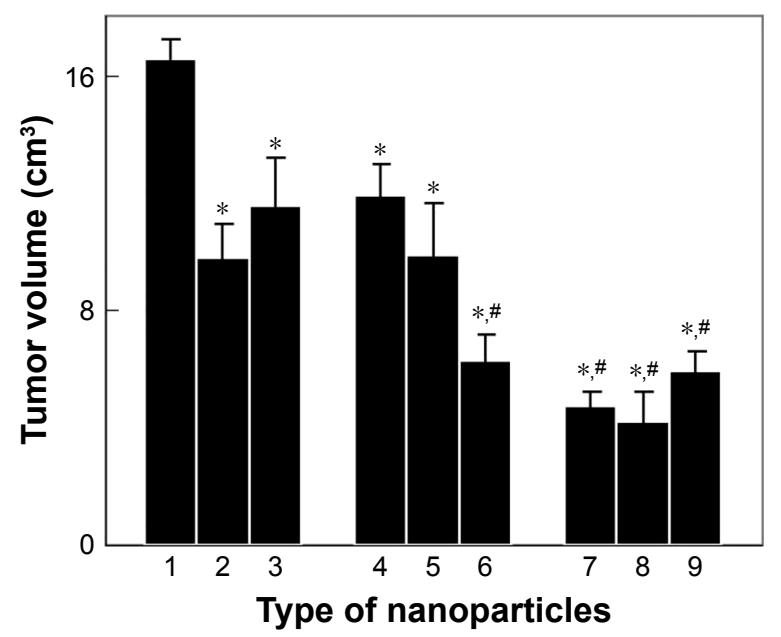

Figure 7 In vivo antitumor activity of nanoparticles on Walker-256 mammary gland carcinosarcoma in Wistar rats. (I) No treatment (control), treatment with (2) $1.5 \mathrm{mg}$ of doxorubicin, (3) $25 \mathrm{mg}$ of Toc-6-Ac, (4) $10 \mathrm{mg}$ of $\mathrm{CuFe}_{2} \mathrm{O}_{4}$, (5) $10 \mathrm{mg}$ of $\gamma-\mathrm{Fe}_{2} \mathrm{O}_{3}$, (6) $10 \mathrm{mg}$ of $\gamma-\mathrm{Fe}_{2} \mathrm{O}_{3} @ P D M A$, (7) $10 \mathrm{mg}$ of $\mathrm{CuFe}_{2} \mathrm{O}_{4}+25 \mathrm{mg}$ of Toc-6-Ac, (8) $10 \mathrm{mg}$ of $\gamma-\mathrm{Fe}_{2} \mathrm{O}_{3}+25 \mathrm{mg}$ of Toc-6-Ac, or (9) $10 \mathrm{mg}$ of $\gamma-\mathrm{Fe}_{2} \mathrm{O}_{3} @$ PDMA + $25 \mathrm{mg}$ of Toc-6-Ac per kilogram of body weight. Data are presented as the mean $\pm \mathrm{SE}$ $(n=5-7)$. *Significantly different from (I) control animals; " significantly different from 2) animals treated with doxorubicin.

Abbreviation: PDMA, poly(N,N-dimethylacrylamide). 
particles (Figure 5). The highest amount of lipid peroxidation was observed for $\mathrm{CuFe}_{2} \mathrm{O}_{4}$ particles, which exhibited the lowest antitumor activity compared to $\gamma-\mathrm{Fe}_{2} \mathrm{O}_{3}$ and $\gamma-\mathrm{Fe}_{2} \mathrm{O}_{3} @$ PDMA particles.

When considering the mechanism of the antitumor effect of $\gamma-\mathrm{Fe}_{2} \mathrm{O}_{3} @$ PDMA nanoparticles, it is important to note that the particle dispersion has to first pass through the stomach, as described in an earlier report. ${ }^{59}$ Here, we proved that a highly acidic medium that mimicked the stomach conditions did not damage $\gamma-\mathrm{Fe}_{2} \mathrm{O}_{3} @$ PDMA particles due to the protective PDMA shell. The particles could then enter the gastrointestinal tract and blood circulation system to reach organs such as the liver, kidney, and mesentery. ${ }^{60}$ To be resorbed into the blood stream, we speculate that the particles penetrated the mucus barrier of the small intestine due to their small size, which allowed secretion by the epithelium. It is also important to note that the bioaccumulation of iron oxide nanoparticles after oral treatment, which is the most common and natural way of drug delivery, has not yet been described. ${ }^{61}$ Nevertheless, it is known that particles circulating in the bloodstream are preferentially accumulated by tumor cells due to their increased proliferative activity and passive transfer, which is known as the enhanced permeability and retention (EPR) effect. ${ }^{62}$ Differences in cellular uptake between cancer cells and normal cells have been observed by many authors, ${ }^{63}$ although the reasons for these differences are still under investigation. Several studies suggest that this difference may be related to the difference in the endocytosis pathways between normal cells and cancer cells. ${ }^{64,65}$ Within tumor cells, cytotoxic $\mathrm{Fe}^{2+}$ is released under the formation of a singlet oxygen, leading to cell membrane and mitochondrial damage. ${ }^{66}$

To further determine the cytotoxicity of $\mathrm{CuFe}_{2} \mathrm{O}_{4}$, $\gamma-\mathrm{Fe}_{2} \mathrm{O}_{3}$, and $\gamma-\mathrm{Fe}_{2} \mathrm{O}_{3} @$ PDMA nanoparticles (including their combination with Toc-6-Ac) administered to tumor-bearing animals, hepatic indicators (ALT, AST, and bilirubin content) were measured in blood plasma (Figure 8). Compared to control tumor-bearing rats, ALT activity in all groups of treated animals decreased, ultimately reaching the levels in intact control animals (Figure 8A). By contrast, AST activity was only decreased in animals administered nanoparticles and Toc-6-Ac, reaching the levels of intact control rats (Figure 8B). The bilirubin content in the blood plasma of animals treated with the particles was significantly lower compared to that in tumor-bearing rats (Figure 8C), indicating intensified iron metabolism in the liver of treated compared to untreated - animals. Combined administration of the nanoparticles with Toc-6-Ac increased the bilirubin content to the level in intact control animals. These results, thus, demonstrate that the developed nanoparticles orally administered in Wistar rats with Walker-256 carcinosarcoma do not induce toxicity in the liver, which is a dominant organ of nanoparticle accumulation.

To investigate the cytotoxicity of the nanoparticles on white and red blood cells of tumor-bearing rats, hematologic studies were performed. While $\mathrm{CuFe}_{2} \mathrm{O}_{4}$ administration significantly increased the white blood cell counts, likely due to acute inflammation (Figure 9A), other nanoparticles - both neat and in combination with Toc-6-Ac-did not significantly affect this count. By contrast, administration of toxic doxorubicin decreased the white blood cell count (Figure 9A). No marked changes in the red blood cell count were found in tumor-bearing rats after administration of doxorubicin, Toc-6-Ac, $\mathrm{CuFe}_{2} \mathrm{O}_{4}, \gamma-\mathrm{Fe}_{2} \mathrm{O}_{3}, \gamma-\mathrm{Fe}_{2} \mathrm{O}_{3}$ @PDMA, or their combination with Toc-6-Ac (Figure 9B).

\section{Conclusion}

In the present work, alkaline coprecipitation of $\mathrm{FeCl}_{2}$ and $\mathrm{FeCl}_{3}$ aqueous solutions followed by oxidation with $\mathrm{NaOCl}$ produced $\sim 10 \mathrm{~nm}$ superparamagnetic $\gamma-\mathrm{Fe}_{2} \mathrm{O}_{3}$ nanoparticles with a relatively narrow particle size distribution. Subsequently, PDMA was synthesized and used as a coating to improve the colloidal stability of the nanoparticles. Iron oxide nanoparticles are advantageous in that they are not only biocompatible and easily and noninvasively monitored by $\mathrm{MRI}^{67}$ but they can also be simply targeted to a tumor via a magnet. Colorimetric analysis of the $\gamma-\mathrm{Fe}_{2} \mathrm{O}_{3} @$ PDMA nanoparticles confirmed the in vitro release of $\mathrm{Fe}^{2+}$ from the particles that was enhanced in the presence of Toc-6-OH. Thus, we conclude that $\mathrm{Fe}^{2+}$ plays a crucial role in initiating lipid oxidation, as shown by the enhanced blood lipid oxidation in the presence of the tested nanoparticles in vitro. Of the tested particles, $\mathrm{CuFe}_{2} \mathrm{O}_{4}$ oxidized lipids most efficiently.

In vivo, oral administration of Toc-6-Ac to Wistar rats with model Walker-256 mammary gland carcinosarcoma induced similar antitumor effects as those of doxorubicin. The antitumor activity of $\gamma-\mathrm{Fe}_{2} \mathrm{O}_{3} @$ PDMA nanoparticles was significantly higher than that of doxorubicin. The beneficial effect of $\mathrm{Fe}^{2+}$ release from the particles and Toc-6-Ac antitumor activity were, thus, confirmed in vivo and their combined activities documented. It should be noted that, compared to highly toxic compounds, such as doxorubicin, the $\gamma-\mathrm{Fe}_{2} \mathrm{O}_{3} @$ PDMA particles are advantageous in the absence of systemic toxicity. To further monitor the biological effects of both $\gamma-\mathrm{Fe}_{2} \mathrm{O}_{3} @$ PDMA and Toc-6-Ac in vivo, ALT and AST enzyme activities were analyzed in the blood plasma of Wistar rats with Walker-256 carcinosarcoma that were treated as described earlier. All of the investigated 

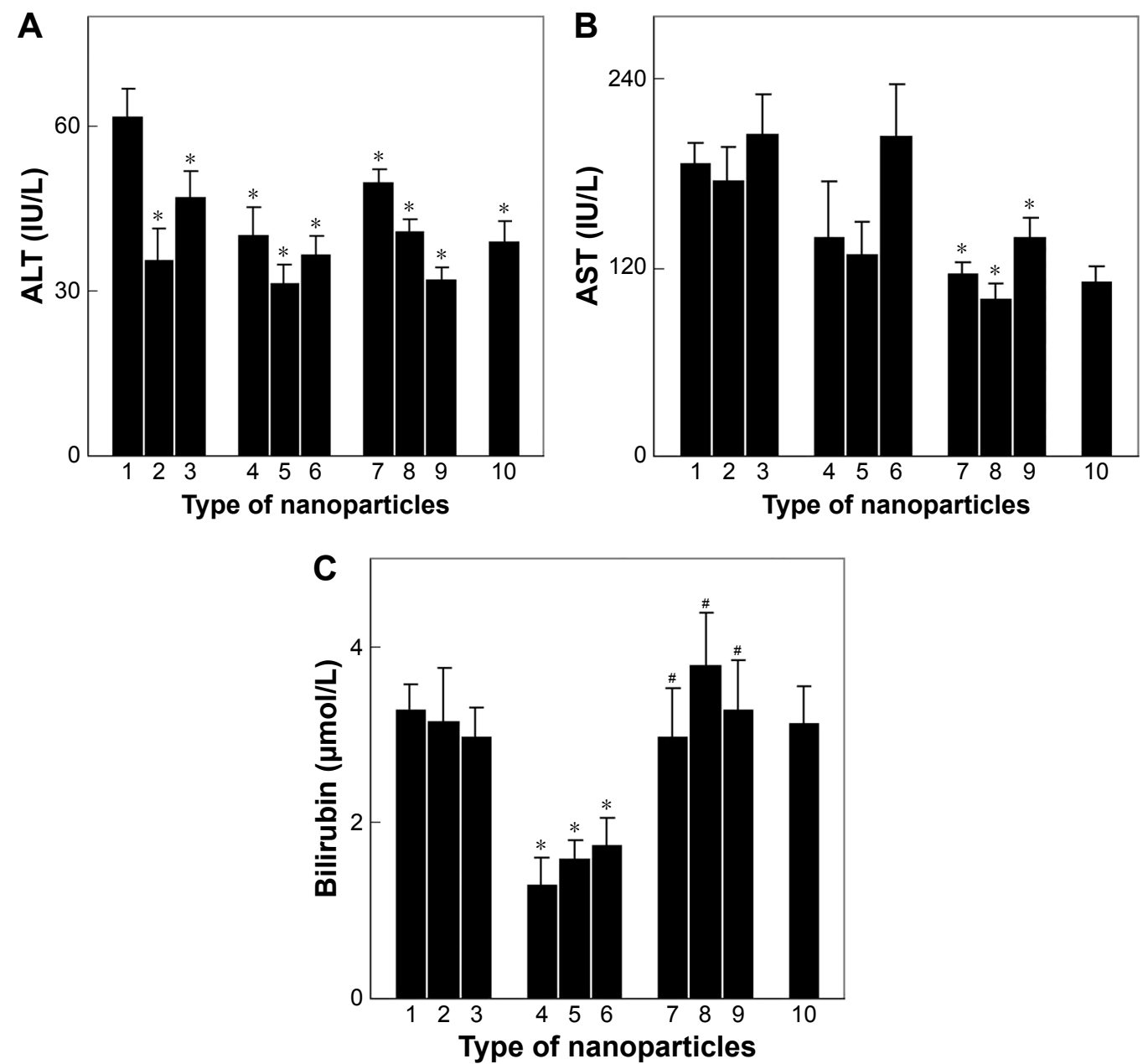

Figure 8 In vivo determination of hepatic function using (A) ALT, (B) AST, and (C) bilirubin analyses of the blood plasma of Wistar rats with Walker-256 mammary gland carcinosarcoma. (I) No treatment (tumor control), treatment with (2) $1.5 \mathrm{mg}$ of doxorubicin, (3) $25 \mathrm{mg}$ of Toc-6-Ac, (4) $10 \mathrm{mg}$ of $\mathrm{CuFe}_{2} \mathrm{O}_{4}$, (5) $10 \mathrm{mg}$ of $\gamma-\mathrm{Fe}_{2} \mathrm{O}_{3}$, (6) $10 \mathrm{mg}$ of $\gamma-\mathrm{Fe}_{2} \mathrm{O}_{3} @ P D M A$, (7) $10 \mathrm{mg}$ of $\mathrm{CuFe}_{2} \mathrm{O}_{4}+25 \mathrm{mg}$ of Toc-6-Ac, (8) $10 \mathrm{mg}$ of $\gamma-\mathrm{Fe}_{2} \mathrm{O}_{3}+25 \mathrm{mg}$ of Toc-6-Ac, or (9) $10 \mathrm{mg}$ of $\gamma-\mathrm{Fe}_{2} \mathrm{O}_{3} @$ PDMA + $25 \mathrm{mg}$ of Toc-6-Ac per kilogram of body weight, and (10) non-treated rats without a tumor (intact control). Data are presented as the mean $\pm \mathrm{SE}(\mathrm{n}=5-7)$. *Significantly different from (I) control animals; " significantly different from (4-6) animals treated with neat nanoparticles.

Abbreviations: ALT, alanine aminotransferase; AST, aspartate aminotransferase; PDMA, poly(N,N-dimethylacrylamide).
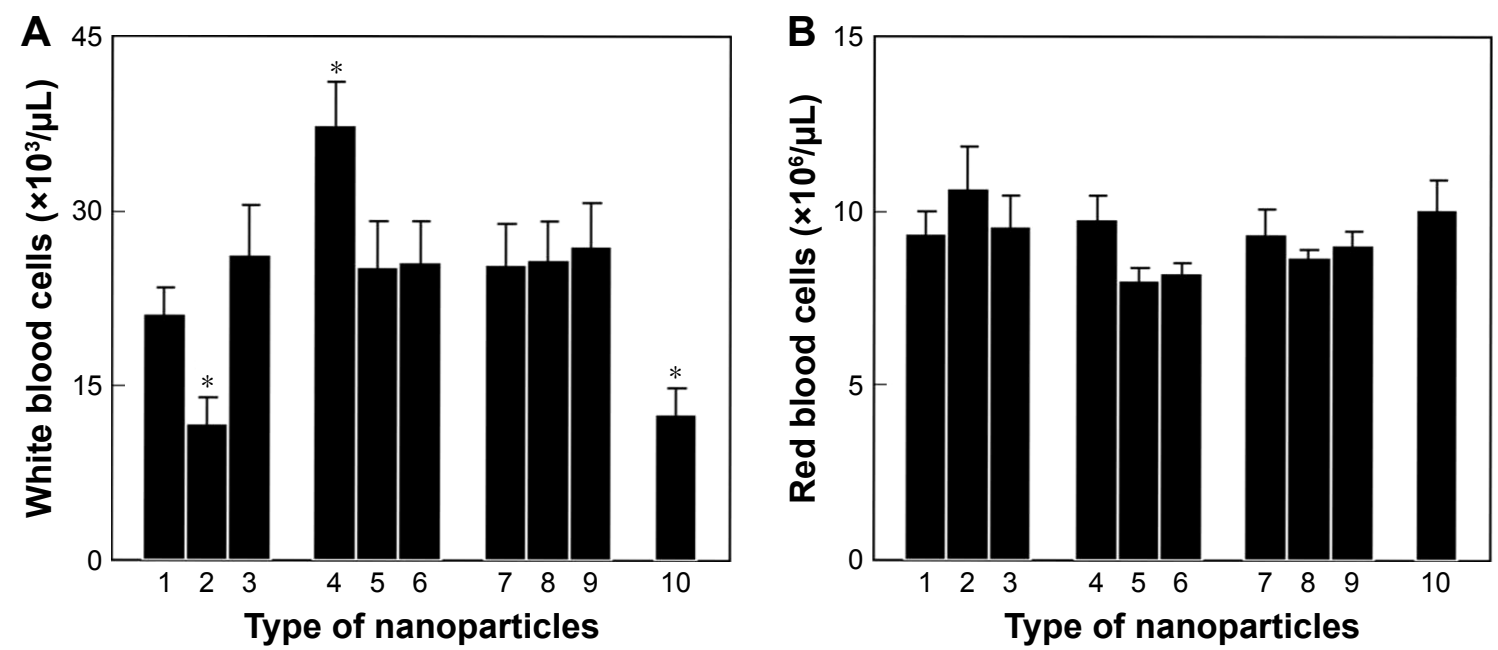

Figure 9 In vivo complete blood count of (A) white and (B) red blood cells in Wistar rats with Walker-256 mammary gland carcinosarcoma. (I) No treatment (control), treatment with (2) I.5 mg of doxorubicin, (3) $25 \mathrm{mg}$ of Toc-6-Ac, (4) $10 \mathrm{mg}$ of CuFe $\mathrm{O}_{4},(5) 10 \mathrm{mg}$ of $\gamma$-Fe $\mathrm{O}_{3},(6) 10 \mathrm{mg}$ of $\gamma$-Fe $\mathrm{O}_{3} @ \mathrm{PDMA}$, (7) I0 mg of CuFe $\mathrm{O}_{4}+25 \mathrm{mg}$ of Toc-6-Ac, (8) 10 mg of $\gamma-\mathrm{Fe}_{2} \mathrm{O}_{3}+25$ mg of Toc-6-Ac, or (9) $10 \mathrm{mg}$ of $\gamma-\mathrm{Fe}_{2} \mathrm{O}_{3} @$ PDMA $+25 \mathrm{mg}$ of Toc-6-Ac per kilogram of body weight, and (I0) non-treated rats without a tumor (intact control). Data are presented as the mean $\pm S E(n=5-7)$. *Significantly different from (I) control animals.

Abbreviation: PDMA, poly(N,N-dimethylacrylamide). 
compounds and their combinations decreased ALT activity in tumor-bearing rats, reaching baseline levels in intact control animals, suggesting the absence of liver dysfunction. In other words, the non-toxicity of the newly developed preparations was confirmed. AST activity decreased only in rats after receiving combined oral administration of the nanoparticles and Toc-6-Ac. This finding was in agreement with blood tests in the presence of $\gamma-\mathrm{Fe}_{2} \mathrm{O}_{3} @$ PDMA particles and Toc-6-Ac, wherein bilirubin levels did not differ from those of intact control animals. Moreover, the white and red blood counts were not affected by administration of $\gamma-\mathrm{Fe}_{2} \mathrm{O}_{3} @$ PDMA, Toc-6-Ac, or both. We, thus, conclude that these promising results can be prospectively employed for the design of a new cancer treatment using the combined administration of $\gamma-\mathrm{Fe}_{2} \mathrm{O}_{3} @$ PDMA nanoparticles and Toc-6-Ac.

\section{Acknowledgments}

The financial support of the Czech Science Foundation (grant 17-04918S), support from the joint research project between the Institute of Macromolecular Chemistry ASCR and the Palladin Institute of Biochemistry NASV in 2014-2016, as well as RECOOP HST Association and Cedars-Sinai Medical Center, is acknowledged.

\section{Disclosure}

The authors report no conflicts of interest in this work.

\section{References}

1. Lozovska YV, Naleskina LA, Lukyanova NY, Todor IM, Chekhun VF Assessment of the geno- and cytotoxic action of colloidal gold nanoparticles on the bone marrow erythroid cell lines and tumors in animals with Ehrlich ascites carcinoma. Cytol Genet. 2015;49(1):42-48.

2. Gupta AK, Gupta M. Synthesis and surface engineering of iron oxide nanoparticles for biomedical applications. Biomaterials. 2005;26(18): 3995-4021.

3. Bui DT, Nicolas J, Maksimenko A, Desmaële D, Couvreur P. Multifunctional squalene-based prodrug nanoparticles for targeted cancer therapy. Chem Commun (Camb). 2014;50(40):5336-5338.

4. Ma P, Mumper RJ. Paclitaxel nano-delivery systems: A comprehensive review. J Nanomed Nanotechnol. 2013;4(2):1000164.

5. Schwertmann U, Cornell RM. Iron Oxides in the Laboratory: Preparation and Characterization. Weinheim: WILEY-VCH; 1991.

6. Reddy LH, Arias JL, Nicolas J, Couvreur P. Magnetic nanoparticles: design and characterization, toxicity and biocompatibility, pharmaceutical and biomedical applications. Chem Rev. 2012;112(11): 5818-5878.

7. Mahmoudi M, Sant S, Wang B, Laurent S, Sen T. Superparamagnetic iron oxide nanoparticles (SPIONs): Development, surface modification and applications in chemotherapy. Adv Drug Deliv Rev. 2011; 63(1-2):24-46.

8. Mao X, Sun H, He X, Chen L, Zhang Y. Well-defined sulfamethazineimprinted magnetic nanoparticles via surface-initiated atom transfer radical polymerization for highly selective enrichment of sulfonamides in food samples. Anal Methods. 2015;7(11):4708-4716.

9. Rho WY, Kim HM, Kyeong S, et al. Facile synthesis of monodispersed silica-coated magnetic nanoparticles. J Ind Eng Chem. 2014;20(5): 2646-2649.
10. Konwarh R, Saikia JP, Karak N, Konwar BK. "Poly(ethylene glycol)magnetic nanoparticles-curcumin" trio: Directed morphogenesis and synergistic free-radical scavenging. Colloids Surf B Biointerfaces. 2010; 81(2):578-586.

11. Mahmoudi M, Simchi A, Imani M. Cytotoxicity of uncoated and polyvinyl alcohol coated superparamagnetic iron oxide nanoparticles. J Phys Chem C. 2009;113(22):9573-9580.

12. Mosaiab T, Jeong CJ, Shin GJ, et al. Recyclable and stable silver deposited magnetic nanoparticles with poly(vinyl pyrrolidone)-catechol coated iron oxide for antimicrobial activity. Mater Sci Eng C Mater Biol Appl. 2013;33(7):3786-3794.

13. Fresnais J, Yan M, Courtois J, Bostelmann T, Bée A, Berret JF. Poly(acrylic acid)-coated iron oxide nanoparticles: quantitative evaluation of the coating properties and applications for the removal of a pollutant dye. J Colloid Interface Sci. 2013;395:24-30.

14. Bach LG, Islam MR, Kim JT, Seo SY, Lim KT. Encapsulation of $\mathrm{Fe}_{3} \mathrm{O}_{4}$ magnetic nanoparticles with poly(methyl methacrylate) via surface functionalized thiol-lactam initiated radical polymerization. Appl Surf Sci. 2012;258(7):2959-2966.

15. Chen JP, Yang PC, Ma YH, Wu T. Characterization of chitosan magnetic nanoparticles for in situ delivery of tissue plasminogen activator. Carbohydr Polym. 2011;84(1):364-372.

16. Tassa C, Shaw SY, Weissleder R. Dextran-coated iron oxide nanoparticles: a versatile platform for targeted molecular imaging, molecular diagnostics and therapy. Acc Chem Res. 2011;44(10):842-852.

17. Kim DK, Mikhaylova M, Wang FH, et al. Starch-coated superparamagnetic nanoparticles as MR contrast agents. Chem Mat. 2003;15(23):4343-4351.

18. Arias JL, López-Viota M, López-Viota J, Delgado AV. Development of iron/ethylcellulose (core/shell) nanoparticles loaded with diclofenac sodium for arthritis treatment. Int J Pharm. 2009;382(1-2):270-276.

19. Iwaki Y, Kawasaki H, Arakawa R. Human serum albumin-modified $\mathrm{Fe}_{3} \mathrm{O}_{4}$ magnetic nanoparticles for affinity-SALDI-MS of small-molecule drugs in biological liquids. Anal Sci. 2012;28(9):893-900.

20. Gaihre B, Khil MS, Lee DR, Kim HY. Gelatin-coated magnetic iron oxide nanoparticles as carrier system: Drug loading and in vitro drug release study. Int J Pharm. 2009;365(1-2):180-189.

21. Donchenko GV, Kholodova YD, Kuzmenko IV, Klymenko KP. Inhibitor of cancer growth. Ukrainian Patent UA 23977. 1998.

22. Constantinidesa PP, Tustianb A, Kessler DR. Tocol emulsions for drug solubilization and parenteral delivery. Adv Drug Deliv Rev. 2004; 56(9):1243-1255.

23. Schwarz K, Huang SW, German JB, Tiersch B, Hartmann J, Frankel EN. Activities of antioxidants are affected by colloidal properties of oil-inwater and water-in-oil emulsions and bulk oils. J Agric Food Chem. 2000;48(10):4874-4882.

24. Yoo SH, Song YB, Chang PS, Lee HG. Microencapsulation of $\alpha$-tocopherol using sodium alginate and its controlled release properties. Int J Biol Macromol. 2006;38(1):25-30.

25. Lambert KJ, Panayiotis PC, Quay SC. Emulsion vehicle for poorly soluble drugs. United States patent US 6458373. 2002 Oct 1.

26. Guo Y, Luo J, Tan S, Otieno BO, Zhang Z. The applications of vitamin E TPGS in drug delivery. Eur J Pharm Sci. 2013;49(2):175-186.

27. Hobbs HK, Huffaker JE, Taggart EM, Papas AM. Water dispersible vitamin E composition. United States patent US 5234695. 1993 Oct 8.

28. Tan YF, Chandrasekharan P, Maity D, et al. Multimodal tumor imaging by iron oxides and quantum dots formulated in poly(lactic acid)-Dalpha-tocopheryl polyethylene glycol 1000 succinate nanoparticles. Biomaterials. 2011;32(11):2969-2978.

29. Covaliu CI, Matei C, Litescu S, et al. Radical scavenger properties of oxide nanoparticles stabilized with biopolymer matrix. Mater Plast. 2010;47(1):5-10.

30. Babič M, Horák D, Jendelová P, et al. Poly( $N, N$-dimethylacrylamide)coated maghemite nanoparticles for stem cell labeling. Bioconjug Chem. 2009;20(2):283-294.

31. Zasonska BA, Boiko N, Horák D, et al. The use of hydrophilic poly $(N, N-$ dimethylacrylamide) grafted from magnetic $\gamma-\mathrm{Fe}_{2} \mathrm{O}_{3}$ nanoparticles to promote engulfment by mammalian cells. J Biomed Nanotechnol. 2012;9:479-491. 
32. Zuo Y, Hoigné J. Formation of hydrogen peroxide and depletion of oxalic acid in atmospheric water by photolysis of iron(III)-oxalato complexes. Environ Sci Technol. 1992;26(5):1014-1022.

33. Walters MI, Gerarde HW. An ultramicromethod for the determination of conjugated and total bilirubin in serum or plasma. Microchem J. 1970;15(2):231-243.

34. Henley KS. IFCC method for alanine aminotransferase. Clin Chim Acta. 1980;105(1):155-166.

35. Bergmeyer HU, Horder M, Moss DW. Provisional recommendations on IFCC methods for the measurements of catalytic concentrations of enzymes. Part 3. Revised IFCC method for aspartate aminotransferase. Clin Chem. 1978;24:720-721.

36. Gelvan D, Saltman P. Different cellular targets for $\mathrm{Cu}$ and Fe-catalyzed oxidation observed using a $\mathrm{Cu}$-compatible thiobarbituric acid assay. Biochim Biophys Acta. 1990;1035(3):353-360.

37. Ke W, Zhao Y, Huang R, Jiang C, Pei Y. Enhanced oral bioavailability of doxorubicin in a dendrimer drug delivery system. J Pharm Sci. 2008; 97(6):2208-2216.

38. Faustino-Rocha A, Oliveira PA, Pinho-Oliveira J, et al. Estimation of rat mammary tumor volume using caliper and ultrasonography measurements. Lab Anim (NY). 2013;42(6):217-224.

39. Close B, Banister K, Baumans V, et al. Recommendations for euthanasia of experimental animals: Part 1. DGXT of the European Commission. Lab Anim. 1996;30(4):293-316.

40. Close B, Banister K, Baumans V, et al. Recommendations for euthanasia of experimental animals: Part 2. DGXT of the European Commission. Lab Anim. 1997;31(1):1-32.

41. Babič M, Horák D, Trchová M, et al. Poly( $L$-lysine)-modified iron oxide nanoparticles for stem cell labeling. Bioconjug Chem. 2008;19(3): 740-750.

42. Pirri G, Damin F, Chiari M, Bontempi E, Depero LE. Characterization of a polymeric adsorbed coating for DNA microarray glass slides. Anal Chem. 2004;76(5):1352-1358.

43. Horák D, Semenyuk N, Lednický F. Effect of the reaction parameters on the particle size in the dispersion polymerization of 2-hydroxyethyl and glycidyl methacrylate in the presence of a ferrofluid. J Polym Sci Polym Chem. 2003;41(12):1848-1863.

44. Hermanson GT, Malia AK, Smith PK. Immobilized Affinity Ligand Techniques. San Diego: Academic Press Inc.; 1992.

45. Yang J, Kopeček J. Backbone degradable and coiled-coil based macromolecular therapeutics. In: Gu Z, editors. Bioinspired and Biomimetic Polymer Systems for Drug and Gene Delivery. Weinheim: Wiley-WCH; 2015.

46. McConnel EL, Basit AW, Murdan S. Measurements of rat and mouse gastrointestinal $\mathrm{pH}$, fluid and lymphoid tissues, and implications for in-vivo experiments. J Pharm Pharmacol. 2007;60(1):63-70.

47. Emmerie A, Engel C. Colorimetric determination of tocopherol (vitamin E). III. Estimation of tocopherol in blood serum. Rec Trav Chim. 1939;58(10):895-902.

48. Mizushima Y, Takama K, Zama K. Effect of copper, iron and hemin on lipid oxidation in fish flesh homogenate. Bull Fac Fish Hokkaido Univ. 1977;28(4):207-211.

49. Lauridsen C, Hedemann MS, Jensen SK. Hydrolysis of tocopheryl and retinyl esters by porcine carboxyl ester hydrolase is affected by their carboxylate moiety and bile acids. J Nutr Biochem. 2001;12(4): 219-224.

International Journal of Nanomedicine

\section{Publish your work in this journal}

The International Journal of Nanomedicine is an international, peerreviewed journal focusing on the application of nanotechnology in diagnostics, therapeutics, and drug delivery systems throughout the biomedical field. This journal is indexed on PubMed Central, MedLine, CAS, SciSearch $®$, Current Contents ${ }^{\circledR} /$ Clinical Medicine,
50. Muller DP, Manning JA, Mathias PM, Harries JT. Studies on the intestinal hydrolysis of tocopheryl esters. Int J Vitam Nutr Res. 1976;46: 207-210.

51. Macková H, Horák D, Donchenko GV, et al. Colloidally stable surfacemodified iron oxide nanoparticles: Preparation, characterization and anti-tumor activity. J Magn Magn Mater. 2015;380:125-131.

52. Torti SV, Torti FM. Iron and cancer: More ore to be mined. Nat Rev Cancer. 2013;13(5):342-355.

53. Mojžišová G, Mojžiš J, Vašková J. Organometallic iron complexes as potential cancer therapeutics. Acta Biochim Pol. 2014;61(4): 651-654.

54. Ludwig H, Evstatiev R, Kornek G, et al. Iron metabolism and iron supplementation in cancer patients. Wien Klin Wochenschr. 2015; 127(23-24):907-919.

55. Zhu MT, Wang Y, Feng WY, et al. Oxidative stress and apoptosis induced by iron oxide nanoparticles in cultured human umbilical endothelial cells. J Nanosci Nanotechnol. 2010;10(2):8584-8590.

56. Fenton HJH. Oxidation of tartaric acid in presence of iron. J Chem Soc Trans. 1894;65:899-911.

57. Wang J, Pantopoulos K. Regulation of cellular iron metabolism. Biochem J. 2011;434(3):365-381.

58. Voinov MA, Sosa Pagán JO, Morrison E, Smirnova TI, Smirnov AI. Surface-mediated production of hydroxyl radicals as a mechanism of iron oxide nanoparticle biotoxicity. J Am Chem Soc. 2011;133(1):35-41.

59. Ensign LM, Cone R, Hanes J. Oral drug delivery with polymeric nanoparticles: The gastrointestinal mucus barriers. Adv Drug Deliv Rev. 2012;64(6):557-570.

60. Hughes MF, Long TC, Boyes WK, Ramabhadran R. Whole-body retention and distribution of orally administered radiolabeled zerovalent iron nanoparticles in mice. Nanotoxicology. 2013;7(6):1064-1069.

61. Singh SP, Rahman MF, Murty US, Mahboob M, Grover P. Comparative study of genotoxicity and tissue distribution of nano and micron sized iron oxide in rats after acute oral treatment. Toxicol Appl Pharmacol. 2013;266(1):56-66.

62. Duncan R, Sat YN. Tumour targeting by enhanced permeability and retention (EPR) effect. Ann Oncol. 1998;9(Suppl 2):39.

63. Zhang Q, Rajan SS, Tyner KM, et al. Effects of iron oxide nanoparticles on biological responses and MR imaging properties in human mammary healthy and breast cancer epithelial cells. J Biomed Mater Res B Appl Biomater. 2016;104(5):1032-1042.

64. Gao H, Yang Z, Zhang S, et al. Ligand modified nanoparticles increases cell uptake, alters endocytosis and elevates glioma distribution and internalization. Sci Rep. 2013;3:2534.

65. Raoof M, Mackeyev Y, Cheney MA, Wilson LJ, Curley SA. Internalization of C60 fullerenes into cancer cells with accumulation in the nucleus via the nuclear pore complex. Biomaterials. 2012;33(10):2952-2960.

66. Xu C, Yuan Z, Kohler N, Kim J, Chung MA, Sun S. FePt nanoparticles as an Fe reservoir for controlled Fe release and tumor inhibition. $J \mathrm{Am}$ Chem Soc. 2009;131(42):15346-15351.

67. Li L, Jiang W, Luo K, et al. Superparamagnetic iron oxide nanoparticles as MRI contrast agents for non-invasive stem cell labeling and tracking. Theranostics. 2013;3(8):595-615.

Journal Citation Reports/Science Edition, EMBase, Scopus and the Elsevier Bibliographic databases. The manuscript management system is completely online and includes a very quick and fair peer-review system, which is all easy to use. Visit http://www.dovepress.com/ testimonials.php to read real quotes from published authors. 